\title{
SERVIR A DEUS OU A MAMON: UMA ANÁLISE EXEGÉTICA DE LUCAS 16:9-13
}

Serving God or Mammon: an Exegetical Analysis of Luke 16: 9-13

Luiz Felipe Xavier*

RESUMO: A perícope de Lucas 16:9-13 apresenta três ensinos de Jesus aos seus discípulos. O primeiro é que façam amigos com o Mamon da injustiça, o segundo, que sejam fiéis e não sejam injustos no uso de Mamon, e o terceiro, que sirvam a Deus e não a Mamon. Este último é o clímax dos dois primeiros. O objetivo do presente artigo é fazer uma análise exegética dessa perícope. Para tal, será utilizado o método histórico-crítico: a apresentação dos critérios de delimitação da perícope, a tradução e a estruturação do texto, a crítica textual, a crítica literária, a crítica da redação, a crítica da forma, a crítica da tradição e a análise do conteúdo. Ao final, serão apresentadas duas importantes antíteses que explicitam parte do chamado à conversão proposto por Jesus no Evangelho de Lucas: da acumulação à doação e do serviço a Mamon ao serviço a Deus.

PALAVRAS-CHAVE: Conversão. Acumulação. Doação. Serviço a Mamon. Serviço a Deus.

ABSTRACT: The pericope of Luke 16:9-13 presents three teachings of Jesus to his disciples. The first is to make friends with the Mammon of injustice, the second is to be faithful and never unjust in the use of Mammon, and the third is to serve God and not Mammon. The last teaching is the climax of the previous two. This article aims to do an exegetical analysis of this pericope using the historical-critical method: starting with the criteria for delimiting the pericope, the translation and structure of the text, and a series of criticisms on the text, its literary aspect, redaction, form and tradition, followed by a content analysis. To conclude, two

\footnotetext{
* Faculdade Jesuíta de Filosofia e Teologia, Belo Horizonte, Minas Gerais, Brasil.
} 
important antitheses will be presented that explain part of the call to conversion proposed by Jesus in the Gospel of Luke: from accumulation to donation and from service to Mammon to service to God.

KEYWORDS: Conversion. Accumulation. Donation. Service to Mammon. Service to God.

\section{Introdução}

A perícope de Lucas 16:9-13, que trata de três ensinos de Jesus aos - 1 seus discípulos, é precedida por Lucas 16:1-8, que trata da Parábola do Administrador Astuto, e sucedida por Lucas 16:14-15, que trata da repreensão de Jesus aos fariseus. Embora no texto não haja uma clara mudança de indicação cronológica, topográfica e de personagens, ele pode ser delimitado dessa maneira pelas seguintes razões:

a) Mudanças de indicações de conteúdos gerais:

Em Lucas 16:1-8, o conteúdo geral é o elogio à atitude de renunciar aos bens materiais para ganhar o favor das pessoas, ilustrado na Parábola do Administrador Astuto. Em Lucas 16:9-13, o conteúdo geral são os três ensinamentos de Jesus aos seus discípulos sobre a relação destes com Mamon. E, em Lucas 16:14-15, o conteúdo geral é uma repreensão aos fariseus, denominados amigos do dinheiro.

b) Mudanças de indicações de ações:

Em Lucas 16:1-8, Jesus fala aos seus discípulos lançando mão de uma parábola. Em Lucas 16:9-13, Jesus continua falando aos seus discípulos, mas agora, lançando mão de uma série de ditos. E em Lucas 16:14-15, Jesus deixa de falar aos seus discípulos e passa a falar aos fariseus, lançando mão de mais um dito.

No que se refere à delimitação inicial da perícope de Lucas 16:9-13, os exegetas não chegam a um consenso. Isso porque há dúvidas sobre o fim da Parábola do Administrador Astuto (Lc. 16:1-8). De acordo com Joseph Fitzmyer, a exegese moderna apresenta quatro possibilidades para esse fim. Primeira possibilidade: a unidade compreende os v. 1-9. De 1-7, tem-se a parábola propriamente dita e, de 8-9, tem-se a aplicação da parábola. Segunda possibilidade: a unidade compreende os v. 1-7. O restante é uma adição posterior à parábola. Terceira possibilidade: a unidade compreende os v. 1-8. Essa possibilidade inclui tanto o elogio do senhor ao seu administrador quanto o contraste entre os filhos deste século e os filhos da luz. Quarta possibilidade: a unidade compreende os v. 1-8a. Ela exclui o contraste entre os filhos deste século e os filhos da luz (1987b, p. 694-696). Fitzmyer concorda com a quarta possibilidade de delimitação. Logo, para ele, ao invés da perícope em questão começar em 16:9, ela deve começar em 16:8b. 
Diferentemente de Fitzmyer, François Bovon concorda com a primeira possibilidade apresentada pela exegese moderna para o fim da Parábola do Administrador Astuto. Ou seja, que a unidade compreende os v. 1-9. Assim, segundo Bovon, ao invés da perícope em questão começar em 16:9, ela deve começar em 16:10. De modo diverso a Fitzmyer e Bovon, Kenneth Bailey concorda com a terceira possibilidade. Isto é, a unidade compreende os v. 1-8. Assim sendo, conforme Bailey, ao invés da perícope ter início em 1:8a ou em 1:10, ela deve começar em 1:9. Esta será a opção adotada aqui. A favor dela está o membro: Kai ' $\varepsilon \gamma \omega$ ù uîv $\lambda \varepsilon^{\prime} \gamma \omega,(\mathrm{E}$ eu digo a vós:), no v. 9a. No Evangelho segundo Lucas, esse membro é uma fórmula introdutória solene ${ }^{1}$. Aqui, ele conecta o fim da Parábola do Administrador Astuto (v. 8) ao início dos três ensinos de Jesus aos seus discípulos dela decorrentes (v. 9b). Consequentemente, é válido dizer que a delimitação da perícope é Lucas 16:9-13.

\section{Tradução $o^{2}$ estruturação}

\section{Lucas 16:9-13}

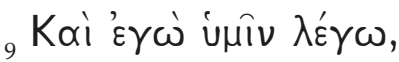

${ }_{9}$ E eu digo a vós:

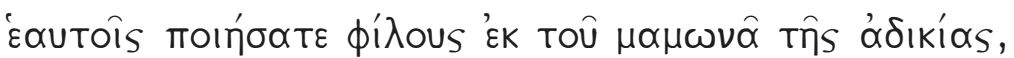

Para vós mesmos, fazei amigos com o Mamon da injustiça,

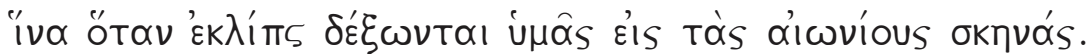

para que quando [este] cessar eles recebam a vós nos eternos tabernáculos.

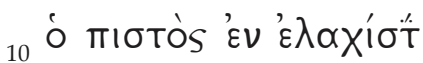

${ }_{10}$ o fiel no pouco,

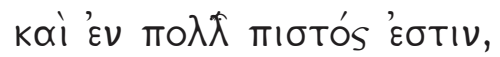

também no muito fiel é.

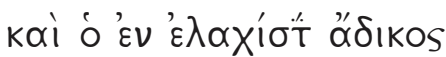

E o no pouco injusto,

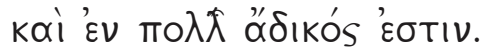

também no muito injusto é.

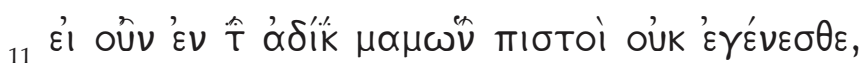

${ }_{11}^{11}$ Portanto, se no injusto Mamon, fiéis não vos tornardes,

\footnotetext{
${ }^{1}$ Cf. Lc. 5:24; 6:27; 11:9.

2 Para esta tradução foram consultadas as seguintes obras: 1) NESTLE, E.; ALAND, K. (Org.). Novum Testamentum Graece: 27th. Ed. Stuttgart: Deutsche Bibelgesellschaft, 1993. 2) ALAND, Barbara et al. O Novo Testamento grego: quarta edição revisada - com introdução em português e dicionário grego-potuguês. Barueri: Sociedade Bíblica do Brasil, 2009. 3) LUZ, Waldyr Carvalho (Org.). Novo Testamento Interlinear. São Paulo: Cultura Cristã, 2004. 4) FRIBERG, Barbara; FRIBERG, Timothy. O Novo Testamento grego analítico. São Paulo: Vida Nova, 1987. 5) KONINGS, Johan. Sinopse dos Evangelhos de Mateus, Marcos e Lucas e da "Fonte Q". São Paulo: Loyola, 2005b. Todas as traduções são lineares ao texto grego, priorizando a literalidade.
} 


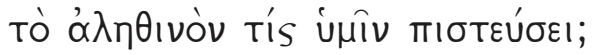

o verdadeiro, quem vos confiará?

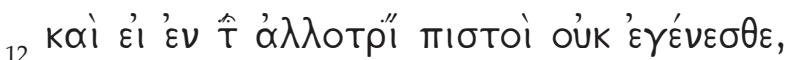

${ }_{12}$ E se no alheio, fiéis não vos tornardes,

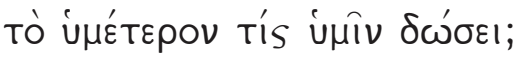

o vosso, quem vos dará?

13

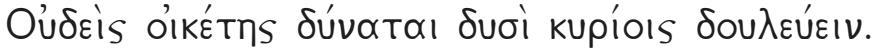

Nenhum servo pode a dois senhores servir,

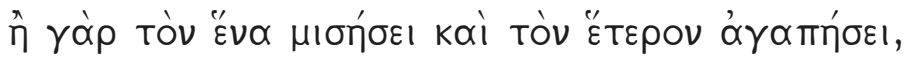
pois ou o um odiará e o outro amará,

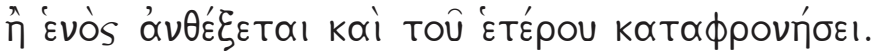

ou [a] um se apegará e do[ao] outro desprezará.

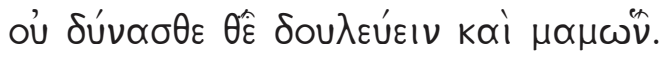

Não podeis a Deus servir e a Mamon.

\section{Crítica textual}

De acordo com Roger L. Omanson, apenas um termo da perícope de Lucas

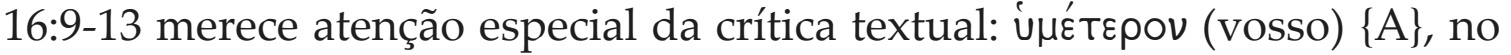
v. 12. Acerca desse termo, ele afirma:

A variante $\hat{\eta} \mu \varepsilon^{\prime} \tau \varepsilon \rho o v$ (nosso) tem todo jeito de ser um refinamento teológico posterior (= "pertencer ao Pai e ao Filho") que expressa a origem divina das riquezas verdadeiras (v. 11). Parece que a leitura marcionita $\varepsilon \mu o ́ v(m e u)$ também reflete essa perspectiva teológica. É mais provável, todavia, que co-

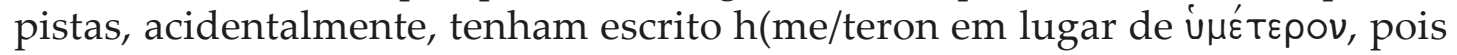
no grego mais recente as vogais $u$ e $\eta$ passaram a ter a mesma pronúncia. O contexto favorece a leitura de ú $\mu \dot{\varepsilon} \tau \varepsilon \rho o v$, pois a antítese correta para "dos

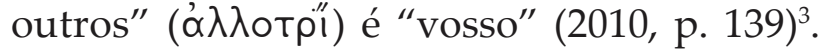

\section{Crítica literária}

Considerando que a perícope de Lucas 16:9-13 ${ }^{4}$ foi delimitada no tópico 1 e estruturada no tópico 2, resta a apresentação de um esquema dessa estrutura.

\footnotetext{
${ }^{3}$ Cf. tb. METZGER, 2006, p. 140.

${ }^{4}$ Essa perícope apresenta 18 verbos, 8 substantivos, 8 adjetivos, 14 conjunções e 8 preposições. Dos 18 verbos, 5 estão no aoristo, 7 no presente, 6 no futuro e 1 no imperfeito. Das 14 conjunções, 5 são subordinativas, 8 são coordenativas e 1 (uma) é superordenativa ou hiperordenativa.
} 
Fórmula introdutória (v. 9a)

Primeiro ensino de Jesus (v. 9b)

Segundo ensino de Jesus (v. 10-12)

Chave enunciativa (v. 10)

Chave interrogativa (v. 11-12)

Terceiro ensino de Jesus (v. 13)

A série de três ensinos de Jesus aos seus discípulos começa com uma fórmula introdutória (v. 9a; cf. tb. Lc. 16:1a). Todos eles são sobre a relação dos discípulos de Jesus com Mamon. O primeiro ensino se refere ao uso que os discípulos devem fazer de Mamon (v. 9b). Eles devem usá-lo para fazer amigos (à semelhança do que fora ensinado na Parábola do Administrador Astuto). $\mathrm{O}$ segundo ensino se refere às atitudes dos discípulos a respeito de Mamon (v. 10-12). Eles devem ser fiéis e justos no uso do pouco que lhes for confiado no presente. $\mathrm{O}$ terceiro ensino se refere ao serviço dos discípulos a Deus ou a Mamon (v. 13). Dada a impossibilidade de serviço a Deus e a Mamon, eles devem decidir a quem servirão: a um ou a outro.

No que tange a esse esquema, Fitzmyer comenta:

Já desde o início da tradição evangélica se adicionaram à parábola do administrador astuto (Lc. 16:1-8a) alguns ditos dispersos de Jesus. [...] No contexto do Evangelho segundo Lucas se adicionam três aplicações concretas da parábola: v. 8b-9; 10-12; 13. [...] Em si mesmas, valem já como testemunho de um processo interpretativo de caráter moralizante, que foi ganhando espaço na comunidade cristã primitiva. Não cabe dúvida de que as aplicações procedem, originalmente, de contextos distintos; mas pelo menos a primeira delas se vincula muito à parábola propriamente dita $\left(1987 b\right.$, p. $\left.710^{5}\right)$.

\section{Crítica da redação}

Na perícope de Lucas 16:9-13, a fórmula introdutória, v. 9a, o primeiro ensino de Jesus, v. 9b, e o segundo ensino de Jesus, v. 10-12, não possuem paralelos sinópticos. Ou seja, podem ser consideradas obras do próprio Lucas. Já o terceiro ensino de Jesus, v. 13, possui um paralelo sinóptico direto em Mateus 6:24. Então, uma vez que um paralelo sinóptico direto de Lucas está presente em Mateus e ausente em Marcos, a fonte de ambos é Q.

Quanto ao segundo ensino de Jesus, obra do próprio Lucas, Fitzmyer diz:

Sua pertença à fonte “L" parece indiscutível [...]. É possível que os v. 10-12 pertenciam, originalmente, ao contexto dos "servos fiéis e vigi-

\footnotetext{
${ }^{5}$ Esta e todas as demais citações diretas de Fitzmyer são traduções do autor deste artigo.
} 
lantes" (Lc. 12:35-48). Mas aqui, de fato, constituem uma unidade - a segunda aplicação - literalmente vinculada à anterior pelo enlace verbal: mamōna tês adikias (= "dinheiro de injustiça, iniquidade": v. 9) e [en] tō adikō mamōna (= "o dinheiro injusto, iníquo" do v. 11) (1987b, p. 711-712).

E no que se refere ao terceiro ensino de Jesus, cuja fonte é $Q$, Bovon afirma:

A origem do dito sobre os dois senhores (v. 13) é mais fácil de determinar: trata-se da Fonte dos logia, como atesta o paralelo de Mt. 6:24. O parentesco entre os dois evangelhos sinópticos é aqui tal, que ambos se apoiam em uma mesma forma grega de $Q$, mais provavelmente escrita do que oral. A única diferença é que Lucas, instalado ainda na linguagem figurada, precisa que a pessoa incapaz de servir a dois senhores é um "servo doméstico" (o’kÉTnS). [...] O lugar desta frase na Fonte dos logia é difícil de determinar. A posição no evangelho segundo Lucas parece corresponder a motivos de redação: o evangelista (ou, antes dele, o autor do material próprio) constrói um conjunto referido à administração fiel dos bens e recorre à palavra gancho Mamon (v. 9,11,13) $\left(2004, \text { p. } 119^{6}\right)^{7}$.

\section{Crítica da forma}

Lucas 16:9-13 pertence ao grande gênero literário denominado Evangelhos. Dentro desse gênero há um subgênero: ditos ou lógia. Nesse subgênero, há ditos sapienciais ${ }^{8}$ (v. 9; 10-129; 13). Como já observado, esses ditos sapienciais podem ser divididos em: 1) princípios ou axiomas; 2) exortações; e 3) perguntas. Na perícope em questão há princípios ou axiomas, v. $10^{10}$ e 13 (forma afirmativa), exortações, v. 9 (forma imperativa) e perguntas, v. 11 e 12 (forma interrogativa).

Corroborando, em parte, com isso, Fitzmyer comenta:

Desde o ponto de vista da história das formas, as três aplicações adicionadas à parábola poderiam considerar-se, globalmente, como "máximas sapienciais" de Jesus [...]. Só uma delas (v. 9) é claramente "exortativa", por sua formulação no imperativo; as demais são de caráter "declarativo" (1987b, p. 713).

\footnotetext{
${ }^{6}$ Esta e todas as demais citações diretas de Bovon são traduções do autor deste artigo.

${ }^{7}$ Cf. tb. FITZMYER, 1987b, p. 712.

8 "Sua origem provém da tradição sapiencial do AT, corrente também entre os rabinos do tempo de Jesus [...]. [R.] Bultmann diferencia três formas de ditos sapienciais: Princípios ou axiomas. Sua forma é afirmativa. [...] Exortações. Sua forma é imperativa. [...] Perguntas. Sua forma é interrogativa." (WEGNER, 2012, p. 243-244).

9 "Com um estilo totalmente diferente, os logia dos v. 10-12 se parecem por seu caráter sapiencial com ditos dos capítulos anteriores (por exemplo: 11:36; 12:2-3, etc.)." (BOVON, 2004, p. 96).

${ }^{10}$ Bovon considera que o v. 10a é um provérbio. Provavelmente, Lucas o insere para fazer um contraponto à infidelidade do administrador da parábola precedente (2004, p. 118).
} 
Diferentemente da proposta apresentada acima, Fitzmyer inclui os v. 11 e 12 nos princípios e axiomas. Porém, dadas as suas formulações interrogativas, optou-se por incluí-los nas perguntas.

A respeito do Sitz im Leben ou lugar vivencial, pouco se sabe ${ }^{11}$. Ao que parece, ele é a catequese. Isso por duas razões: primeira, porque os destinatários das palavras de Jesus são os seus discípulos; segunda, porque o conteúdo das palavras de Jesus corresponde a três ensinos sobre a relação desses discípulos com Mamon. Esses ensinos devem ser aprendidos e praticados no ambiente da comunidade de fé.

\section{Crítica da tradição}

No que tange à crítica da tradição de Lucas 16:9-13, apenas dois destaques se fazem necessários: um em relação à fórmula introdutória e ao primeiro ensino de Jesus (v. 9); e outro em relação ao segundo ensino de Jesus (v. 10-12). Acerca da fórmula introdutória e do primeiro ensino de Jesus, Bovon diz: "Como atesta o vocabulário arcaico, este v. 9 deve remontar a uma fase arameia oral da primeira igreja da Palestina." (BOVON, 2004, p. 98). Na mesma linha de Bovon, Fitzmyer afirma: "A fraseologia é marcadamente semítica, com um claro transfundo palestinense [...]" (FITZMYER, 1987b, p. 711). Dois exemplos disso são $\mu \alpha \mu \omega \nu \widehat{\alpha}$ Tñs ådı́ías (Mamon da

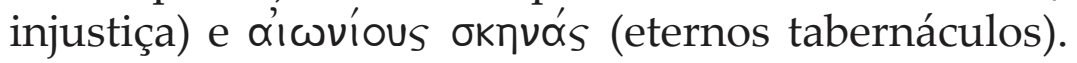

Sobre o segundo ensino de Jesus, Fitzmyer comenta:

Sua formulação é indiscutivelmente prelucana. Nos v. 10 e 11, a antítese se desenvolve entre pistos/pisteuein (= "fiel", "o que é fiável / confiável") e adikos (= "injusto", "o que não é honrado"), enquanto que no v. 12 - à parte de sua coincidência com os precedentes na repetição de pistoi - a polaridade da antítese se centra no tō allotriō (= "o alheio") e tō hymeteron (= o vosso) (1987b, p. 711).

Ainda acerca dos v. 10-12, Bovon acrescenta:

Como uma parte da terminologia destes versículos, com seus neutros ("o verdadeiro", "o alheio", "o vosso"), parece estranha ao vocabulário do Mestre, é

${ }^{11}$ Discutindo a função dos v. 10-12, Bovon menciona, de passagem, os cristãos de então: “Os logia dos v. 10-12 podem servir também de comentários. Mas, diferentemente dos v. 8b e 9, tiveram uma existência independente antes de serem vinculados à parábola e aos seus comentários em razão de suas afinidades temática (o motivo da administração) e formal (os vocábulos 'Mamon' e 'injusto' = lit. 'da injustiça'). Certamente, a união não foi conseguida sem problemas, posto que estes v. 10-12 celebram a honradez, enquanto que a parábola se inclinava até certa imoralidade. Porém, os cristãos de então os utilizavam precisamente como ajuda para eliminar o duplo equívoco da parábola, melhor do que faziam os v. 8a, 8b, e 9. Além disso, essa ligação deve ter exigido certa mudança formal: o v. 10b, que destaca a implausibilidade (ninguém confia grandes bens a quem não soube administrar uma fortuna pequena!), poderia ter sido criado para favorecer a adequação no momento da união do $\mathrm{v}$. 10a com a parábola." (2004, p. 98). 
preciso contemplar uma transformação substancial da formulação de Jesus. Esta releitura deve ter acontecido em torno do autor do material próprio, ao que atribuo a redação destes versículos ausentes dos outros evangelhos (2004, p. 119).

\section{Análise do conteúdo}

A perícope de Lucas 16:9-13 se encontra na viagem de Jesus da Galileia à Judeia. Essa viagem começara em Lucas 9:51: “Quando se completaram os dias de sua assunção, ele tomou resolutamente o caminho de Jerusalém [...]". O evangelista introduz essa perícope com a fala de Jesus aos

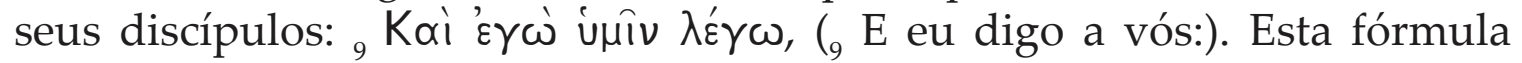
introdutória marca o fim da Parábola do Administrador Astuto e o início dos três ensinos de Jesus aos seus discípulos. Considerando o contexto, o termo $\lambda \varepsilon^{\prime} \gamma \omega$ (digo) refere-se a Jesus e o termo úpiv (a vós) refere-se aos discípulos. Isso fica evidente a partir de Lucas 16:1a: “Dizia ainda [Jesus] a seus discípulos". Os três ensinos de Jesus presentes nessa perícope referem-se à relação dos seus discípulos com o Mamon.

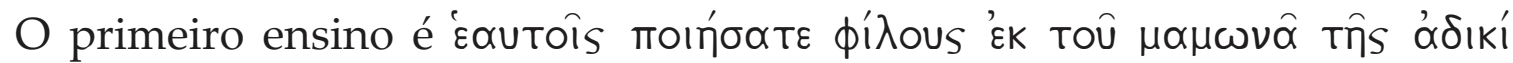
$\alpha_{S}$, (Para vós mesmos, fazei amigos com o Mamon da injustiça,). Nele está

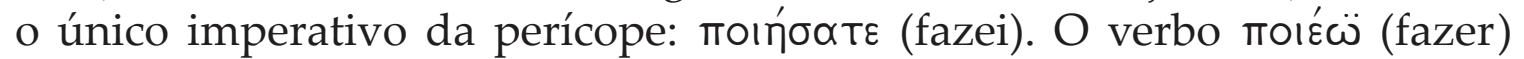
tem vários sentidos. Três desses sentidos, do mais amplo ao mais restrito, merecem atenção. O primeiro é "fazer ou realizar (altamente genérico para praticamente todo o tipo de atividade) - 'fazer, agir, executar, praticar, realizar, feito, realização'." (LOUW; NIDA, 2013, p. 455). O segundo é "ganhar através de trabalho pessoal ou investimentos - 'ganhar, lucrar, ter lucros'." (LOUW; NIDA, 2013, p. 516). O terceiro é "agir ou portar-se de determinada forma em relação a alguém - 'portar-se em relação a, lidar com, fazer a (alguém), agir'." (LOUW; NIDA, 2013, p. 449). Embora esses três sentidos tenham, direta ou indiretamente, alguma relação com o verbo по $\varepsilon \omega$ (fazer) nessa perícope, o seu melhor sentido parece ser o terceiro. Isso porque ele pressupõe relações interpessoais. Jesus ordena aos seus discípulos que façam amigos e, para tal, eles devem utilizar o Mamon da injustiça. Sobre essa ordem, Bovon comenta: "Com toda sua autoridade ('eu digo a vós'), o Cristo lucano insta seus ouvintes a fazer amigos com a ajuda dos bens materiais e lhes promete como recompensa os benefícios espirituais no além." (BOVON, 2004, p. 105-106).

Aqui é necessário considerar o membro toû $\mu \alpha \mu \omega v \hat{\alpha}$ тทิs $\alpha$ dikías (o Mamon da injustiça). O termo $\mu \alpha \mu \omega \nu \hat{\alpha}$ (Mamon) tem apenas quatro entradas no Novo Testamento, sendo três nessa perícope (v. 9, 11 e 13) e uma em Mateus 6:24 (paralelo sinóptico desse v. 13). Quanto a esse termo, Bovon diz:

Mamon é um vocábulo de origem semítica ausente na Bíblia hebraica, mas cujo uso se estende na época do Novo Testamento. Sua etimologia é incerta, porém, 
bem poderia ser a mesma que a nossa palavra "amém". Algo no qual alguém tem confiança, com o qual pode contar. E como os humanos contam com o dinheiro, a palavra passou a designar os bens materiais. Seguindo a atitude crítica de diversas correntes cristãs primitivas frente ao dinheiro, este termo sempre se emprega de maneira negativa no Novo Testamento (2004, p. 106) ${ }^{12}$.

Nos escritos rabínicos, Mamon significa tanto o "dinheiro", em sentido restrito, quanto as "posses", em sentido amplo. Essas "posses" são tudo aquilo que tem preço ou tudo aquilo que o ser humano possui além do seu corpo e da sua vida (BROWN, 2000,v. 2, p. 1716)3. Estes dois significados podem comunicar uma noção de neutralidade. Todavia, como já dito, a utilização neotestamentária do termo Mamon é sempre negativa. Isso fica evidente pelo acréscimo do termo o’ $\delta ı$ ki $_{\text {s }}$ (injustiça), formando

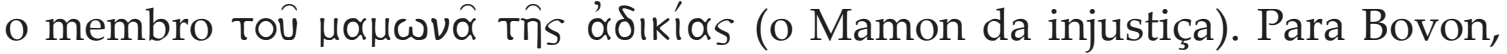
esse membro significa "um dinheiro mal adquirido" (2004, p. 105-106). Ele destaca a origem injusta do Mamon ${ }^{13}$. Ronaldo L. Colavecchio vai além e afirma: "A implicação é que a riqueza tem uma história de injustiça que alguém cometeu contra alguém, e isso tende a continuar!" (2013, p. 91). Essa história de injustiça leva à acumulação excessiva. Contudo, a acumulação excessiva é pecado. Ela é uma expressão clara da desobediência à lei econômico-social do jubileu (cf. Lv. 25). Portanto, Jesus ensina aos seus discípulos que, ao invés de acumular o Mamon da injustiça, eles devem usá-lo para fazer amigos.

O texto segue e a finalidade desse primeiro ensino de Jesus é apresentada:

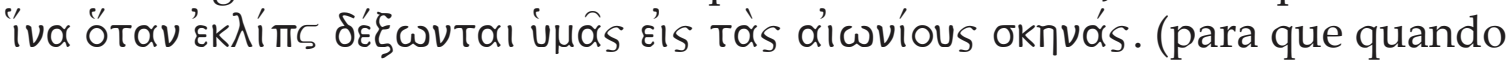
[este] cessar eles recebam a vós nos eternos tabernáculos.). Essa finalidade é evidenciada pelo uso da cojunção subordinativa final İva (para). Os discípulos devem fazer amigos com o Mamon da injustiça para que esses amigos os recebam nos eternos tabernáculos. Aqui, Jesus indica que o Mamon cessará. Esta cessação pode ser interpretada tanto na perspectiva do presente quanto na perspectiva do futuro. Na perspectiva do presente, a cessação se refere a uma situação de crise ou a um apuro (FITZMYER, 1987b, p. 719). Essa é a perspectiva que melhor se adequa à Parábola do Administrador Astuto (Lc. 16:1-8). Já na perspectiva do futuro, a cessação se refere à morte. Acerca disso, Bovon comenta: “[...] a cessação é deliciosamente ambígua: o dinheiro perde sua função quando chega a nossa morte; é a hora por excelência na qual o dinheiro nada vale. É também a hora na qual [...] é bom poder contar com os amigos." (2004, p. 107). Essa é a perspectiva que melhor se adequa a essa perícope.

Logo, no presente, os discípulos devem usar o Mamon da injustiça para ganhar amigos. No futuro, quando morrerem e o Mamon da injustiça nada

${ }^{12}$ Cf. tb. FITZMYER, 1987b, p. 718-719.

${ }^{13}$ Morris segue na mesma linha de interpretação (Cf., 2006, p. 234-235). 
valer, esses amigos os receberão nos eternos tabernáculos. Sobre quem são esses amigos, há três possíveis interpretações sintetizadas por Colin Brown:

Neste versículo, "esses [amigos]" [1] talvez se refira àqueles que receberam benefício de semelhante emprego das riquezas, ou [2] talvez seja um hebraísmo que se refere a Deus sem diretamente mencionar o Seu nome, ou [3] talvez se refira a Deus com seus anjos. O argumento é no sentido de que, embora não haja durabilidade nas próprias riquezas, podem ser empregadas para realizar alguma coisa de valor permanente (2000, p. 1716).

Dessas três possíveis interpretações, a primeira é a mais provável. Isso porque é necessário que haja uma continuidade entre os amigos feitos pelos discípulos no presente e os amigos que recebem os discípulos no futuro. Jesus diz que essa recepção futura se dará nos eternos tabernáculos. Na história do povo de Israel, o tabernáculo é tanto um lugar de encontro com Deus (cf. Êx. 25-26; 33:7) quanto um lugar de encontro do povo de Deus. Entretanto, como os tabernáculos aos quais Jesus se refere são eternos, seu sentido é escatológico. Assim, segundo Bovon, esses tabernáculos eternos podem significar "o lugar ao qual ascendem os crentes após sua morte; ou bem o lugar no qual os fiéis serão acolhidos na parusia." (2004, p. 108).

Tendo concluído seu primeiro ensino, Jesus passa ao segundo. Aqui, ele lança mão de um enunciado (v. 10) e de duas perguntas retóricas (v.

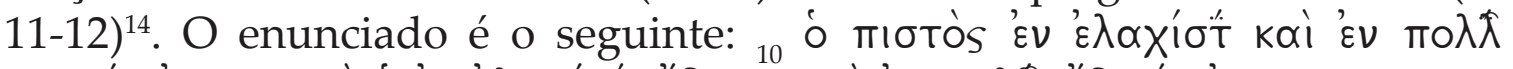

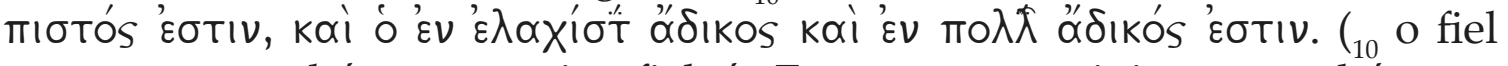
no pouco, também no muito fiel é. $\mathrm{E}$ o no pouco injusto, também no muito injusto é.). Nesse enunciado, Jesus utiliza um paralelismo antitético maior composto por dois paralelismos antitéticos menores. $\mathrm{O}$ foco do primeiro paralelismo menor é colocado sobre a fidelidade. Positivamente, aquele que é fiel no pouco também é fiel no muito. A antítese se dá entre o pouco e o muito. Já o foco do segundo paralelismo menor é colocado sobre a injustiça. Negativamente, aquele que é injusto no pouco também é injusto no muito. Mais uma vez, a antítese se dá entre o pouco e o muito. Como já mencionado, esses dois paralelismos antitéticos menores formam um paralelismo antitético maior. Nesse paralelismo maior, a antítese se dá entre a fidelidade e a injustiça. Assim sendo, Jesus ensina aos seus discípulos, tanto positiva quanto negativamente, qual atitude eles devem ter e qual atitude que eles não devem ter. Isto é, eles devem ser fiéis e não devem ser injustos.

\footnotetext{
${ }^{14}$ É possível que exista uma relação entre Lucas 16:10-12 e Lucas 12:42b-46. Neste último texto, está escrito: “Qual é, então, o administrador fiel e prudente que o senhor constituirá sobre o seu pessoal para dar em tempo oportuno a ração de trigo? Feliz aquele servo que o senhor, ao chegar, encontrar assim ocupado! Verdadeiramente, eu vos digo, ele o constituirá sobre todos os seus bens. Se aquele servo, porém, disser em seu coração: 'O meu senhor tarda a vir', e começar a espancar servos e servas, a comer, a beber e a se embriagar, o senhor daquele servo virá em dia imprevisto e em hora ignorada; ele o partirá ao meio e lhe imporá a sorte dos infiéis.".
} 
Considerando a importância destes dois adjetivos no ensino de Jesus, é válido atentar para os seus significados. Conforme Johannes Louw e Eugene Nida, o adjetivo mıotós (fiel) é "relativo a ser digno de confiança - 'fiel, confiável, digno de confiança'." (2013, p. 455). Já o adjetivo ớઠikos (injusto) é "relativo a não ser correto ou justo -'injusto, injustamente'." (2013, p. 662). O texto não é claro em relação a que os discípulos devem ser fiéis e não devem ser injustos. Mas, tanto no v. 9 quanto no v. 11, Mamon é mencionado. Consequentemente, a fidelidade e a não injustiça devem estar relacionadas ao uso de Mamon. Ou seja, o confiável é aquele que usa o Mamon para fazer amigos e o não correto é aquele que acumula para si o Mamon.

Aprofundando o seu segundo ensino, Jesus faz duas perguntas retóricas

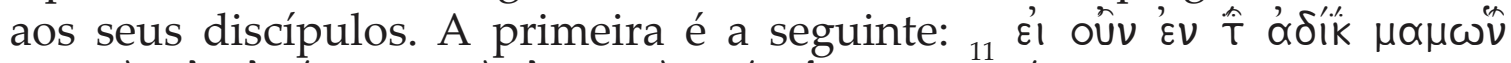

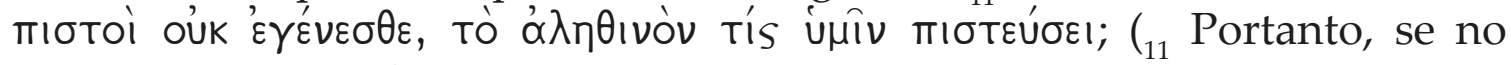
injusto Mamon, fiéis não vos tornardes, o verdadeiro, quem vos confiará?). A resposta a essa pergunta é ninguém. Isto é, ninguém confiará o verdadeiro a quem não é fiel no injusto. Essa primeira pergunta retórica é composta por um paralelismo antitético. Nesse paralelismo, a antítese se dá entre o injusto e o verdadeiro. Aqui, um detalhe deve ser observado: quando a referência é à injustiça presente, o dinheiro é chamado de Mamon, porém, quando a referência é à verdade futura, a riqueza não é nomeada. Ao que parece, isso se deve à dimensão histórica e à dimensão escatológica constitutivas do ensino de Jesus. Ou seja, Mamon só tem valor no presente histórico. Todavia, no futuro escatológico, ele não terá valor algum. Isso porque a verdadeira riqueza será espiritual, não material.

Então, à luz do contexto, ser fiel no injusto Mamon é usá-lo para fazer amigos no presente. Aquele que assim o usa receberá a verdadeira riqueza no futuro. Nessa primeira pergunta retórica, há um jogo de palavras com a raiz do termo Mamon. Acerca disso, Brown afirma:

A palavra gr. mamōnas [...] traduz a forma enfática māmônā do Aramaico māmôn. [...]. [Ela pode estar ligada ao] vb. 'āman, no sentido de "aquilo em que se confia", mas [também pode significar] "aquilo que é confiado ao homem", ou "aquilo que sustenta e alimenta o homem". [...] Em Lc 16:11 parece haver um jogo de palavras com esta raiz: "Se, pois, não vos tornastes fiéis [pistou] na aplicação das riquezas [mamōnas] de origem injusta, quem vos confiará [pisteusei] a verdadeira [alēthinon] riqueza?" As três palavras gr., pistoi, pisteusei e alèthinon traduzem palavras da mesma raiz ' $m n$ da qual se forma "Mamon" (2000, p. 1715-1716).

A segunda pergunta retórica que Jesus faz aos seus discípulos é a seguin-

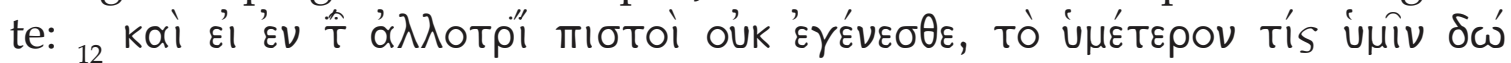
$\sigma \varepsilon ı ;{ }_{12}$ E se no alheio, fiéis não vos tornardes, o vosso, quem vos dará?). A resposta a essa pergunta também é: ninguém. Isto é, ninguém confiará a alguém o que é seu se esse alguém não é fiel no que é de outrem. 
Essa segunda pergunta retórica também é composta por um paralelismo antitético. Nesse paralelismo, a antítese se dá entre o alheio e o vosso. Aqui, mais um detalhe deve ser observado: o Mamon que alguém pensa possuir no presente não lhe pertence de fato. Na verdade, esse alguém que está de posse do Mamon está apenas exercitando a mordomia. Sobre essa mordomia, Leon L. Morris comenta:

Diríamos que, se não formos fiéis em nossas próprias coisas, não estamos em condições de manusear as doutras pessoas. Jesus inverte esta ordem. $\mathrm{O}$ dinheiro do qual pensamos que somos donos não é realmente nosso. [...] Se o manusearmos incorretamente, mostramos que não estamos prontos para usar as verdadeiras riquezas [...] (2006, p. 192).

Nessas duas perguntas, há um presente histórico e um futuro escatológico. Isso significa que as ações de alguém no presente determinarão as reações de outro alguém no futuro. Ou seja, aquele que é fiel no Mamon injusto e alheio, no presente, receberá a riqueza verdadeira e própria no futuro. A pergunta é: receberá de quem? Respondendo a essa pergunta, Bovon diz:

A dupla pergunta é evidentemente retórica: ninguém confia o mais importante a quem tem administrado mal o menos importante. Sobretudo Deus, que se esconde e se manifesta no tís ("quem?"). Como na parábola das minas (19:1127), o autor pensa sem dúvida na repartição dos bens escatológicos efetuada pelo Senhor (2004, p. 123).

Uma vez concluído seu segundo ensino, Jesus passa ao terceiro. Aqui, ele anuncia, explica e aplica esse princípio. O anúncio é o seguinte: ${ }_{13}$ Oủozis

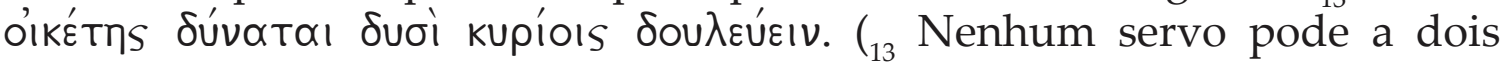
senhores servir,). De acordo com Bovon:

O o’ıźtᄁ - acréscimo lucano a Q (Mt. 6:24) - é um "doméstico" ou um servente que trabalha na casa do seu dono (cf. At. 10:7). Em sentido figurado o vocábulo pode designar todo crente que vive neste mundo [...]. Jesus, o Senhor de Lucas, o que fala na Fonte dos logia, agita os espíritos por seu dualismo cortante e surpreendente. No judaísmo contemporâneo não era possível que um servo pertencesse a dois senhores, segundo o direito de sucessão ou de propriedade. No entanto, os rabinos, ao meditar sobre os mundos terrestre e celeste, diziam com gosto que a maioria das pessoas tinham dois donos, um humano e outro divino. Neste contexto cultural se deve entender o dito de Jesus. Aqui, embora a expressão seja de uma máxima, o peso é de um mandamento. $\mathrm{O}$ aramaico, como o hebraico, opõe "amar" a "odiar" para expressar "preferir", "optar por" ou "ter como prioritário". Jesus convida a se colocar ao lado de Deus: é uma decisão pessoal (2004, p. 123-124).

Portanto, Jesus anuncia aos seus discípulos o princípio de que é impossível servir a dois senhores. A explicação desse princípio é a seguinte: $\hat{\eta} \gamma \alpha \grave{\rho}$

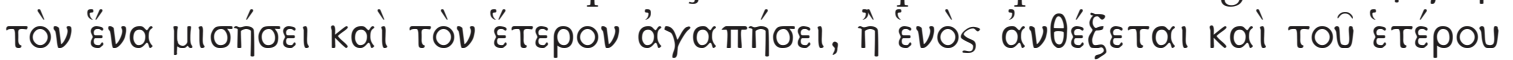

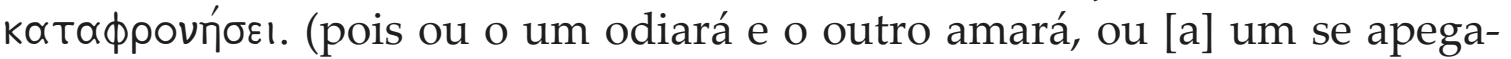
rá e do [ao] outro desprezará.). Essa explicação começa com a conjunção 
subordinativa causal yóp (pois). É impossível servir a dois senhores pois é impossível amar e se apegar a dois senhores simultânea e exclusivamente. Ou se odiará a um e amará ao outro, ou se apegará a um e desprezará ao outro. Nessa explicação, Jesus lança mão de um paralelismo sinonímico em forma de quiasmo clássico ${ }^{15}$. O que se tem é o seguinte:

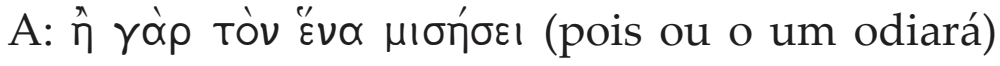

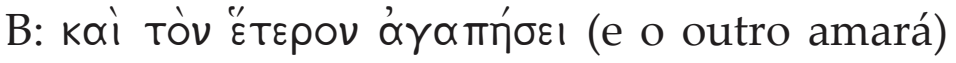

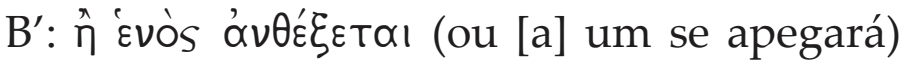

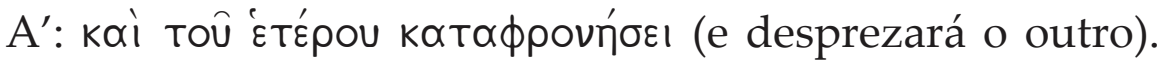

A correspondência entre $A$ e $A^{\prime}$ é evidente pelos termos negativos $\mu$

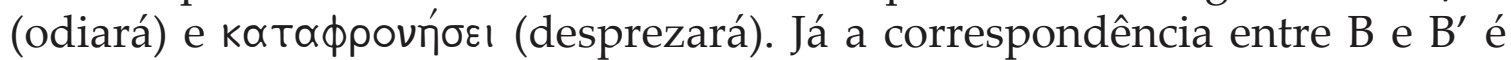

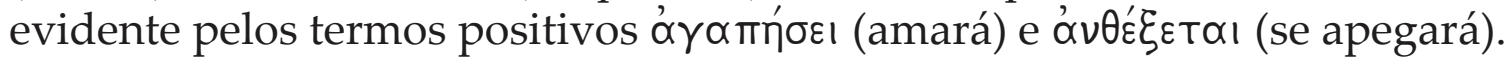
Logo, o serviço a dois senhores é impossível, porque impossíveis são a afeição e a dedicação simultâneas e exclusivas.

Por fim, Jesus aplica o princípio que anunciou e explicou. Essa aplicação é

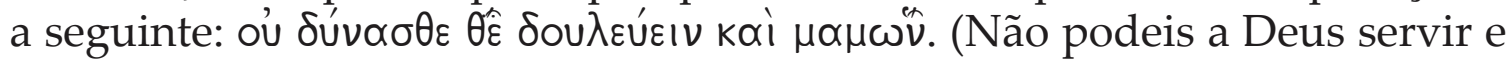
a Mamon.). Aqui, Jesus explicita quais são os dois senhores mencionados no anúncio do princípio. Esses dois senhores são Deus e Mamon. Mais do que isso, ao colocá-los lado a lado, ele personifica Mamon ${ }^{16}$. Este está em antagonismo àquele. Contudo, como Mamon não pode ser Deus, ele é considerado como um ídolo ou um falso deus. Ele é alguém que disputa a afeição e a dedicação que devem ser exclusivas ao Deus único e verdadeiro. Assim, diante de Deus e de Mamon, é necessário decidir a quem servir.

Para Fitzmyer, o verbo $\delta o u \lambda \varepsilon u ́ \varepsilon ı$ (servir) tem uma conotação diversa nesse terceiro ensino de Jesus. Ele afirma:

Sublinhamos unicamente a conotação diversa do verbo douleuein (= "servir"): com referência a Deus, indica uma dependência que enaltece, uma dedicação que consagra; com referência ao dinheiro, é uma escravidão que degrada, uma obsessão que acaba por esmagar. Na parábola seguinte (Lc. 16:19-31, a figura do rico é a encarnação do que significa essa escravidão (1987b, p. 721).

Nesta mesma linha, sobre o antagonismo entre Deus e Mamon, Pagola comenta:

O Dinheiro, convertido em ídolo absoluto, é para Jesus o grande inimigo do projeto humanizador de Deus. Daí seu grito provocativo: "Não podeis servir

\footnotetext{
${ }^{15} \mathrm{O}$ quiasmo é uma construção de simetria total. Mais especificamente, é uma construção em espelho. Essa figura de comparação é semelhante à construção concêntrica, no entanto, sem o elemento central. Um quiasmo clássico é uma construção que compreende apenas quatro unidades: A B | B' $\mathrm{A}^{\prime}$.

16 "Aqui, no v. 13, Mamon representa menos uma realidade material que uma entidade mitológica." (BOVON, 2004, p. 124-125).
} 
a Deus e ao Dinheiro". A lógica de Jesus é contundente. Deus não pode ser Pai de todos sem reclamar justiça para aqueles que são excluídos de uma vida digna. Por isso não podem servi-lo aqueles que, dominados pelo Dinheiro, afundam injustamente seus filhos e filhas na miséria e na fome. Jesus está falando dos círculos herodianos e dos poderosos proprietários de terras de Séforis e Tiberíades, e das grandes famílias sacerdotais do bairro residencial de Jerusalém. Ele vê no Dinheiro um ídolo monstruoso que ele chama de Mamona [...] Parece que se chamava mamona - dinheiro que dá segurança - ao tesouro de moedas de ouro e prata acumuladas pelos ricos para proporcionar-lhes segurança, poder e honra. Era impossível entesourar mamona nas aldeias da Galileia, onde só alguns podiam fazer-se com moedas de bronze e cobre, de escasso valor, e onde a maioria subsitia intercambiando seus produtos do campo (2014b, p. 31-32).

Assim sendo, ao ensinar sobre a relação com Mamon no caminho da Galileia à Judeia, Jesus ajuda seus discípulos a interpretar tanto o que ficou para trás quanto o que estará à frente, em Jerusalém.

\section{Conclusão: duas antíteses}

A primeira antítese que explicita o chamado de Jesus à conversão no seu ensino acerca do dinheiro em Lucas 16:9-13 é da acumulação à doação. Por sua extensão e ênfase, essa antítese pode ser considerada como o clímax do ensino de Jesus acerca do dinheiro no Terceiro Evangelho. A doação é uma atitude concreta que expressa a conversão do coração à generosidade.

Em Lucas 16:9a está o fim da Parábola do Administrador Astuto e o início de três ensinos de Jesus aos seus discípulos. Nessa parábola, Jesus elogia o administrador que abriu mão do seu lucro excessivo para ganhar a amizade daqueles que deviam muito ao seu senhor. Tendo contado essa parábola, Jesus ensina aos seus discípulos como deve ser o relacionamento deles com Mamon, esse ídolo personificado no dinheiro.

Em tom imperativo, o primeiro ensino de Jesus aos seus discípulos está em Lucas 16:9b: façam amigos com o Mamon da injustiça ${ }^{17}$. Ao invés de serem usados pelo Mamon da injustiça, os discípulos devem usá-lo para fazer amigos. Ou seja, o dinheiro que eles têm acumulado excessivamente,

\footnotetext{
17 “Eis, portanto, as qualificações desse Mamom: ele é essencialmente 'de iniquidade'. [1] a injustiça, o contrário da obra de Deus, é a marca específica de Mamom. [2] Trata-se, então, de um Mamom de mentira [...] Ele pertence ao mundo da escuridão e conduz o homem à escuridão e o mantém pela força da mentira. De maneira geral, na perspectiva bíblica, essa mentira se manifesta através do fato de que Mamom é uma potência que engana o homem incessantemente. Ele desperta em si mesmo um desejo que nunca é saciado. [...] Mamom retira do rico a sua própria vida, enquanto lhe dá mais dinheiro. E ele engana ainda o homem ao tentar se fazer passar por aquilo que é estável, pela verdadeira solidez, pelo que merece confiança." (ELLUL, 2008, p. 87).
} 
o que é pecado, deve ser utilizado para iniciar novos relacionamentos. Em assim fazendo, quando morrerem e o Mamon da injustiça nada valer, os discípulos serão recebidos nos eternos tabernáculos por esses novos amigos, por esses que receberam os benefícios da boa utilização que eles fizeram do dinheiro. Esses eternos tabernáculos se referem ao lugar para onde os crentes vão após a sua morte ou ao lugar onde eles serão acolhidos na segunda vinda de Cristo.

A segunda antítese que explicita o chamado de Jesus à conversão no seu ensino acerca do dinheiro em Lucas 16:9-13 é do serviço a Mamon ao serviço a Deus. Certamente, esta é a antítese mais desenvolvida na literatura que aborda a temática do dinheiro. Como observado, em Lucas 16:13, Jesus conclui uma série de três ensinos. No último desses ensinos, ele declara: nenhum servo pode servir a dois senhores ${ }^{18}$. Isso porque é impossível amar e se apegar a dois senhores simultânea e exclusivamente. Ou se odiará a um e amará ao outro, ou se apegará a um e desprezará ao outro. Ou seja, o serviço a dois senhores é impossível porque impossíveis são a afeição e a dedicação simultâneas e exclusivas ${ }^{19}$.

Conforme Jacques Ellul, a questão aqui é de fidelidade: "Ser fiel é seguir a lei e a vontade de seu mestre. Ora, estamos diante de dois mestres possíveis: Mamom e Deus. Cada um tem sua lei e cada um tem a sua vontade. Logo, há duas fidelidades possíveis, duas conformidades possíveis." (2008, p. 99). Obviamente, como esses mestres são opostos entre si, a fidelidade a um exclui a fidelidade ao outro. Por isso, Jesus declara aos seus discípulos: vocês não podem servir a Deus e a Mamon. De acordo com Ellul:

O que Jesus nos revela aqui é que o dinheiro é um poder. Este termo deve ser compreendido não no sentido vago de força, mas no sentido muito específico, corrente no Novo Testamento. [1] O poder é o que age por si mesmo, que é capaz de mover uma outra coisa, que possui uma autonomia (ou finge ter), que segue sua própria lei e se apresenta como sujeito ${ }^{20}$. Essa é uma primeira característica. [2] Uma segunda, é que o poder tem um valor espiritual. Ele não pertence somente ao mundo material (embora aja sobre ele). Ele possui um sentido espiritual, ou seja, por um lado, uma significação espiritual, e por outro, uma direção. O poder não é jamais neutro, ele é orientado e da mesma forma orienta os homens. [3] Enfim, o poder é mais ou menos pessoal. [...]. Logo, este não é um poder pelo fato do homem dele se servir, ou por ser

\footnotetext{
${ }^{18}$ Bovon, influenciado por Ambrosio de Milão, declara: “Com respeito aos v. 10-13: os seres humanos não são proprietários, mas administradores. De fato, só há um verdadeiro dono, Deus. O segundo, Mamon, não é mais do que um déspota ao qual os humanos se oferecem como escravos. Diz-se que o dinheiro é iníquo, porque excita nossa tendência à avareza e nos incita a cair em sua escravidão. As riquezas nos são estranhas, posto que, ao ser de uma natureza distinta da nossa, não nascem nem morrem conosco. Cristo é nosso, pois é a vida." (2004, p. 134)

19 "Amar o dinheiro, se apegar a ele, é odiar a Deus." (ELLUL, 2008, p. 88).

20 "Jesus não descreve uma relação do homem com um objeto, mas com um sujeito." (ELLUL, 2008, p. 80).
} 
ele o meio da fortuna, pois a acumulação da moeda permite muitas coisas, etc. Ele é poder antes de tudo isto, e estes signos exteriores não passam de aparências deste poder que possui uma realidade por si mesma (ou pretende ter) (2008, p. 79-80).

Ao colocar esses dois senhores lado a lado, Jesus personifica Mamon e apresenta o seu antagonismo em relação a Deus. Contudo, como Mamon não é Deus, ele só pode ser um ídolo ou um falso deus. Ele é alguém que disputa a afeição e a dedicação que devem ser exclusivas ao Deus único e verdadeiro. Para Ellul: "Mamom não é um contra-Deus. Ele é o contrário de Deus no domínio do comportamento, mas não goza de nenhuma igualdade com relação a ele." (2008, p. 98). Frente a Deus e a Mamon, os discípulos precisam decidir a quem servirão ${ }^{21}$.

Recentemente, como fruto da relação entre Teologia e Economia, esse ensino de Jesus acerca do dinheiro tem sido atualizado. A título de informação, dois exemplos podem ser dados. O primeiro exemplo é de Ivo Storniolo, que identifica Mamon com o capital ${ }^{22}$. Segundo ele, o v. 13 é o centro de Lucas 16:

Ele nos convida a fazer uma escolha decisiva e definitiva, porque o Senhor Deus é incompatível com o Senhor Dinheiro. Ou servimos a um ou servimos a outro. Não é possível ficar com os pés em duas canoas. Por quê? Porque Deus e o Dinheiro têm regras diferentes. A regra de Deus é a justiça que cria fraternidade e partilha, para que todos tenham liberdade e vida. A regra do Dinheiro, isto é, do Capital, é a injustiça que gera a não-fraternidade, que dá origem ao poder que oprime, e a não-partilha, que dá origem à riqueza que explora. Opressão e exploração que geram poderosos e ricos ao lado de fracos e miseráveis $\left(1992\right.$, p. 147) ${ }^{23}$.

O segundo exemplo é de Ellul e de Jung Sung, que identificam Mamon com o mercado ${ }^{24}$. Essa identificação é introduzida por Ellul e aprofundada por Sung. Conforme Ellul:

Compreendemos então que as questões levantadas pelo dinheiro não são consideradas na Bíblia, como meramente de ordem moral. Elas são, de fato,

\footnotetext{
21 "A riqueza é simplesmente "engano" [ref. à Parábola dos Tipos de Solo] e um engano sedutor. [...] O engano consiste em acreditar que é possível servir ao homem e ao dinheiro: porque, vista a implicação do homem na revelação que Deus faz de si mesmo e a inseparabilidade do primeiro e do segundo mandamentos, segue-se que, se não se pode servir a Deus e ao dinheiro, também não se pode servir ao homem e ao dinheiro." (FAUS, 2015, p. 89).

${ }^{22}$ Entendido como um bem econômico que pode ser utilizado na produção de outros bens ou serviços.

${ }^{23}$ Outros autores fazem o mesmo. Por exemplo, Clodovis Boff: “[...] o caráter religioso [ou idolátrico] do capitalismo consiste no fato de absolutizar ou idolatrar bens relativos, como são os econômicos." (2014, p. 344).

${ }^{24}$ Entendido como um sistema onde os agentes econômicos (pessoas, empresas, etc.) realizam suas transações. Nesse sistema, duas forças são atuantes: a força da oferta e a força da demanda (ou procura).
} 
e em primeiro lugar, de ordem espiritual. Trata-se de uma relação com um poder, e não de um comportamento em relação a um objeto. [...] Este poder que é o dinheiro estabelece um certo tipo de relação entre os homens e um certo comportamento do homem. Ele cria o que podemos chamar muito amplamente de uma relação de "compra e venda". Tudo neste mundo se paga de uma forma ou de outra. Tudo pode igualmente, de uma forma ou de outra, ser comprado. Tal é o caráter que o poder do dinheiro impõe ao mundo. E vemos então que a moeda é somente um dos meios de ação desta potência [...]. Esse é verdadeiramente o comportamento considerado no mundo como normal. Precisamos de uma troca constante sem a qual não poderíamos mais viver (ELLUL, 2008, p. 81-82).

Ellul afirma que a relação com esse poder que é o dinheiro submete os seres humanos a uma relação de compra e venda, a uma relação de mercado. $\mathrm{O}$ aprofundamento que Sung faz dessa identificação de Mamon com o mercado passa pela compreensão do neoliberalismo atual. Isso porque, de acordo com Sung, um dos principais desafios para o cristianismo hoje é o testemunho da sua esperança em um mundo ainda regido pelo neoliberalismo e marcado pela cultura de consumo (SUNG, 2015, p. 39).

De modo geral, os impérios ou sistemas sociais opressores e totalitários se justificam e se legitimam alegando que não há salvação fora deles. Se isso é verdade, as esperanças de mudanças no mundo se esvaem e todas as formas de exploração se transformam em sacrifícios necessários em nome do cumprimento das leis desses impérios ou sistemas sociais. Em meio a tudo isso, os sofrimentos das pessoas são desconsiderados e se estabelece um processo idolátrico. Sobre isso, Sung comenta:

O atual processo de globalização ainda continua se desenrolando sob a hegemonia da ideologia neoliberal. [...] E um dos aspectos mais visíveis do neoliberalismo é a sua tese de que não há salvação fora do mercado. Isto é, não haveria a possibilidade de desenvolvimento econômico e social fora da obediência estrita às leis do livre mercado (2015, p. 43-44).

Um dos pilares dessa ideologia neoliberal é a teoria da incapacidade humana de conhecer realidades complexas, principalmente os fatores e as relações que tecem um sistema econômico amplo. Por isso, os teóricos do neoliberalismo aplicam ao mercado a teoria da auto-organização dos sistemas complexos. Ou seja, o mercado, como um sistema complexo, se auto-organiza a partir das ações, reações e efeitos intencionais e não intencionais dos agentes econômicos. Tudo isso sem o controle consciente de um agente de fora ou acima desse mercado. Portanto, não deve haver intervenções no mercado. Por exemplo: não deve haver intervenção no mercado para a promoção de justiça social (SUNG, 2015, p. 44-45).

Entretanto, um questionamento é feito aos teóricos do neoliberalismo: como garantir que o mercado sempre gerará os melhores resultados possíveis para a sociedade? A resposta deles é a segunte: “é necessário ter fé no 
mercado e se sujeitar a ele". Logo, o mercado se torna uma divindade à qual os seres humanos, incapazes de conhecer realidades complexas, se sujeitam (SUNG, 2015, p. 46). Para Sung, "a dissolução da noção da justiça social não vem do niilismo ou do ateísmo, mas sim da sacralização do mercado, que nega ao ser humano qualquer direito anterior e superior às leis do mercado e, assim, absolutiza a justiça do mercado, negando a justiça social." (2018, p. 151).

Finalmente, segundo Ellul,

toda a obra de Mamom é rigorosamente inversa à obra de Deus. Dada essa oposição de símbolo, compreende-se porque Jesus estabelece a escolha entre Mamom e Deus. Ele não propõe qualquer outra potência, qualquer outra divindade: mas aquela que se opõe diametralmente à ação de Deus, aquela que faz com que a "não-graça" reine sobre o mundo. É claro que toda potência, toda divindade é de uma certa maneira o contrário de Deus, mas não há nada mais contrário que Mamom, sobre o plano do comportamento. Pois Mamom não saberia estar mais ou menos de acordo com a graça: quando a gratuidade entra no coração do homem, Mamom perde toda razão de ser, todo poder sobre ele. Esta conciliação dos dois é o que o homem sempre busca fazer, mais ou menos, apesar dela ser absolutamente inviável (2008, p. 92).

Assim, o ensino direto de Jesus aos seus discípulos é este: do serviço a Mamon ao serviço a Deus.

\section{Referências}

ALAND, B. et al. O Novo Testamento grego: quarta edição revisada - com introdução em português e dicionário grego-português. Barueri: Sociedade Bíblica do Brasil, 2009.

BAILEY, K. E. As parábolas de Lucas. 3.ed. São Paulo: Vida Nova, 1995.

BAILEY, K. E. Jesus pela ótica do Oriente Médio: estudos culturais sobre os Evangelhos. São Paulo: Vida Nova, 2016.

BOFF, C. O livro do sentido: crise e busca de sentido hoje. São Paulo: Paulus, 2014. v. I.

BROWN, C. Posses. In: COENEN, L.; BROWN, C. (Org.). Dicionário Internacional de Teologia do Novo Testamento. São Paulo: Vida Nova, 2000. v. 2. p. 1715-1717.

BOVON, F. Luc le théologien: vingt-cinq ans de recherches (1950-1975). Paris: Delachaux et Niestle, 1978. (Coll. Le Monde de la Bible)

BOVON, F. L'oeuvre de Luc. Etudes d'exegese et de théologie. Paris: Cerf, 1987.

BOVON, F. El Evangelio Según San Lucas: Lc 1,1-9,50. Salamanca: Sígueme, 1995. v. I.

BOVON, F. El Evangelio Según San Lucas: Lc 9,51-14,35. Salamanca: Sígueme, 2002. v. II. 
BOVON, F. El Evangelio Según San Lucas: Lc 15,1-19,27. Salamanca: Sígueme, 2004. v. III.

BOVON, F. Luc le théologien. Geneve: Labor et fides, 2006.

BOVON, F. El Evangelio Según San Lucas: Lc 19,28-24,53. Salamanca: Sígueme, 2010. v. IV.

COLAVECCHIO, R. Jesus e a comunidade do Reino no Evangelho de São Lucas. 2.ed. São Paulo: Loyola, 2013.

ELLUL, J. O homem e o dinheiro: aprenda a lidar com a origem de todos os males. Brasília: Palavra, 2008.

FAUS, J. I. G. As 10 heresias do catolicismo atual. Petrópolis: Vozes, 2015.

FITZMYER J. A. El Evangelio Según Lucas: Introduccion General. Madrid: Cristiandad, 1986. v. I.

FITZMYER J. A. El Evangelio Según Lucas: Traducción y Comentario. Capítulos 1-8,21. Madrid: Cristiandad, 1987a. v. II.

FITZMYER J. A. El Evangelio Según Lucas: Traducción y Comentario. Capítulos 8,22-18,14. Madrid: Cristiandad, 1987b. v. III.

FITZMYER J. A. El Evangelio Según Lucas: Traducción y Comentario. Capítulos 18,15-24,53. Madrid: Cristiandad, 2005. v. IV.

FRIBERG, B.; FRIBERG, T. O Novo Testamento grego analítico. São Paulo: Vida Nova, 1987.

KONINGS, J. Jesus ou os pobres? (Jo 12,1-8). Perspectiva Teológica, Belo Horizonte, v. 25, n. 66, p. 149-162, maio/ago. 1993.

KONINGS, J. Evangelho segundo João: amor e fidelidade. São Paulo: Loyola, 2005a.

KONINGS, J. Sinopse dos Evangelhos de Mateus, Marcos e Lucas e da "Fonte Q". São Paulo: Loyola, 2005b.

KONINGS, J. A palavra se fez livro. 5.ed. São Paulo: Loyola, 2014.

LOUW, J. P.; NIDA, E. A. Léxico grego-português do Novo Testamento: baseado em domínios semânticos. Barueri: Sociedade Bíblica do Brasil, 2013.

LUZ, W. C. (Org.). Novo Testamento Interlinear. São Paulo: Cultura Cristã, 2003.

METZGER, B. M. Un comentario textual al Nuevo Testamento Griego. Brasil: Sociedades Bíblicas Unidas, 2006.

MORRIS, L. L. Teologia do Novo Testamento. São Paulo: Vida Nova, 2003.

MORRIS, L. L. Lucas: introdução e comentário. São Paulo: Vida Nova, 2006.

NESTLE, E.; ALAND, K. (Org.). Novum Testamentum Graece: 27 ${ }^{\text {th }}$. Ed. Stuttgart: Deutsche Bibelgesellschaft, 1993.

OMANSON, R. L. Variantes textuais do Novo Testamento: análise e avaliação do aparato crítico de "O Novo Testamento Grego". Barueri: Sociedade Bíblica do Brasil, 2010.

PAGOLA, J. A. O caminho aberto por Jesus: Lucas. Petrópolis: Vozes, 2012. 
PAGOLA, J. A. Jesus: aproximação histórica. 7.ed. Petrópolis: Vozes, 2014a.

PAGOLA, J. A. Jesus e o dinheiro. Petrópolis: Vozes, 2014b.

STORNIOLO, I. Como ler o Evangelho de Lucas: os pobres constroem a nova história. São Paulo: Paulus, 1992.

SUNG, J. M. Se Deus existe, por que há pobreza? São Paulo: Reflexão, 2008.

SUNG, J. M. A graça de Deus e a loucura do mundo. São Paulo: Reflexão, 2015.

SUNG, J. M. Idolatria do dinheiro e Direitos Humanos: uma crítica teológica ao novo mito do capitalismo. São Paulo: Paulus, 2018.

WEGNER, U. Exegese do Novo Testamento: manual de metodologia. São Leopoldo: Sinodal, 2012.

Artigo submetido em 27/03/2020 e aprovado em 15/10/2020.

Luiz Felipe Xavier é Doutor em Teologia pela Faculdade Jesuíta de Filosofia e Teologia (2019). Professor da Faculdade Evangélica de Teologia de Belo Horizonte (2005-2008), do Centro Universitário Metodista Izabela Hendrix (2008-2018) e da Faculdade Batista de Minas Gerais (2007-2020). É pastor na Igreja Batista da Redenção, em Belo Horizonte. É pesquisador no grupo "A Bíblia em leitura cristã" da Faculdade Jesuíta de Filosofia e Teologia. Orcid. org/0000-0003-1354-4069. E-mail: luiz.xavier13@gmail.com

Endereço: Rua Conde de Monte Cristo, 32 - Apto. 1202 - torre 02 Ipiranga 31.160-410 Belo Horizonte - MG 